\title{
Central-Variant Posterior Reversible Encephalopathy due to Sulfasalazine: A Case Report
}

\author{
Levent Ocek $^{\mathrm{a}}$ Ufuk Sener $^{\mathrm{a}}$ Burcu S. Demirtas ${ }^{\mathrm{a}}$ Metin M. Ozcelik ${ }^{\mathrm{a}}$ \\ Ozgur Oztekin $^{b}$ Yasar Zorlu $^{a}$ \\ Clinics of ${ }^{a}$ Neurology and ${ }^{b}$ Radiology, Tepecik Education and Research Hospital, Izmir, Turkey
}

\section{Key Words}

Sulfasalazine $\cdot$ Central-variant posterior reversible

encephalopathy syndrome $\cdot$ Magnetic resonance imaging

\begin{abstract}
Objective: To report a rare case with central-variant posterior reversible encephalopathy syndrome due to sulfasalazine. Clinical Presentation and Intervention: A 55-year-old female patient presented with seizure and acute-onset hemiparesia. Thirty days earlier, treatment with sulfasalazine was commenced in response to a diagnosis of psoriatic arthritis. Laboratory examinations were normal. Brain magnetic resonance imaging showed symmetric edema within basal ganglia and thalami with sparing of the cerebral cortices. After stopping the treatment of sulfasalazine, clinical and radiological findings regressed dramatically. Conclusion: This was a case of central-variant posterior reversible encephalopathy syndrome due to sulfasalazine, and atypical imaging findings should be kept in mind for early diagnosis.
\end{abstract}

๑) 2015 S. Karger AG, Basel

\section{KARGER 125}

E-Mail karger@karger.com www.karger.com/mpp

\section{(C) 2015 S. Karger AG, Basel}

1011-7571/15/0246-0578 \$39.50/0

Karger

Open access

This is an Open Access article licensed under the terms of the Creative Commons Attribution-NonCommercial 3.0 Unported license (CC BY-NC) (www.karger.com/OA-license), applicable to the online version of the article only. Distribution permitted for non-commercial purposes only.

\section{Introduction}

Posterior reversible encephalopathy syndrome (PRES) is typically characterized as bilateral symmetrical vasogenic edema in the parietal and occipital lobes $[1,2]$. In recent years, patients with PRES who had involvement of brainstem or basal ganglia lacking cortical or subcortical cerebral edema were reported $[1,3]$. This rare radiological entity had been diagnosed as central-variant PRES [1]. This paper describes a patient with central-variant PRES due to sulfasalazine (SSZ) treatment.

\section{Case Report}

A 55-year-old female patient was admitted to our hospital with seizure, mild headache and acute onset hemiparesia. There was nothing remarkable other than psoriatic arthritis in the medical history. Thirty days earlier, treatment with SSZ ( $\mathrm{g}$ /day) was commenced in response to the diagnosis of psoriatic arthritis. At the time of admission, her blood pressure was $120 / 80 \mathrm{~mm} \mathrm{Hg}$ and her temperature was $37^{\circ} \mathrm{C}$. Her blood pressure was normal during patient monitoring. Neurological examination revealed retrograde amnesia and mild right hemiparesis. The fundoscopic examination was normal. Serum biochemical and hematologic tests were within normal limits. Cerebrospinal fluid (CSF) analysis was also normal and CSF cultures were negative. An electroencephalogram showed

Levent Ocek

Clinic of Neurology, Tepecik Education and Research Hospital

Gaziler Caddesi, 469, Yenisehir

TR-35170 Izmir (Turkey)

E-Mail leventocek66@yahoo.com 

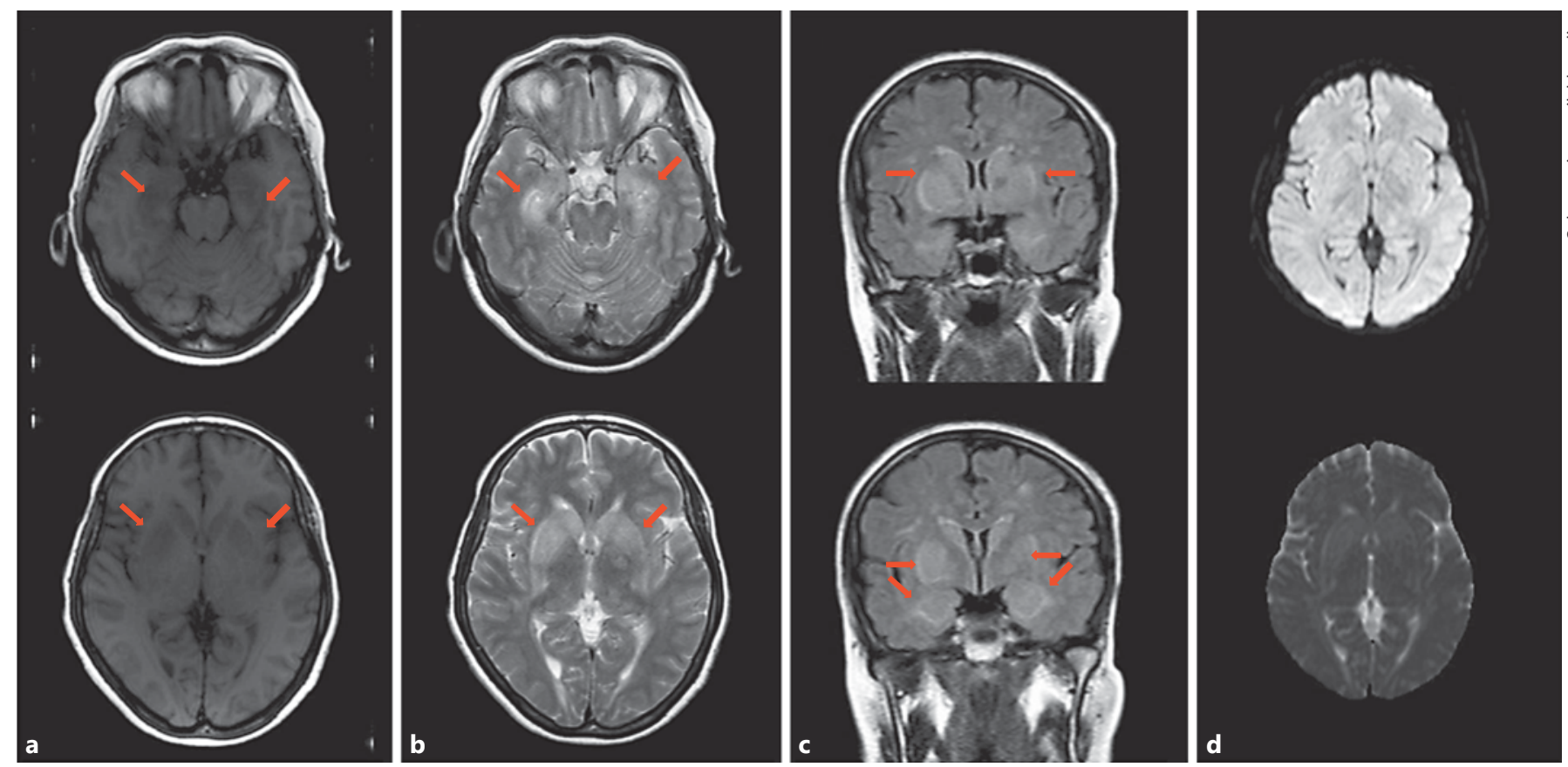

Fig. 1. a On the T1-weighted image, there is subtle hypointensity in affected areas. b On the T2-weighted image, the basal ganglia and thalamus show bilateral and symmetric hyperintense regions. c On the FLAIR image, there is hyperintensity in the same affected areas. $\mathbf{d}$ On diffusion-weighted imaging, there is no diffusion restriction on the affected areas.

Fig. 2. On control MRI taken 4 weeks after the treatment, abnormalities on basal ganglia and thalamus have completely resolved.
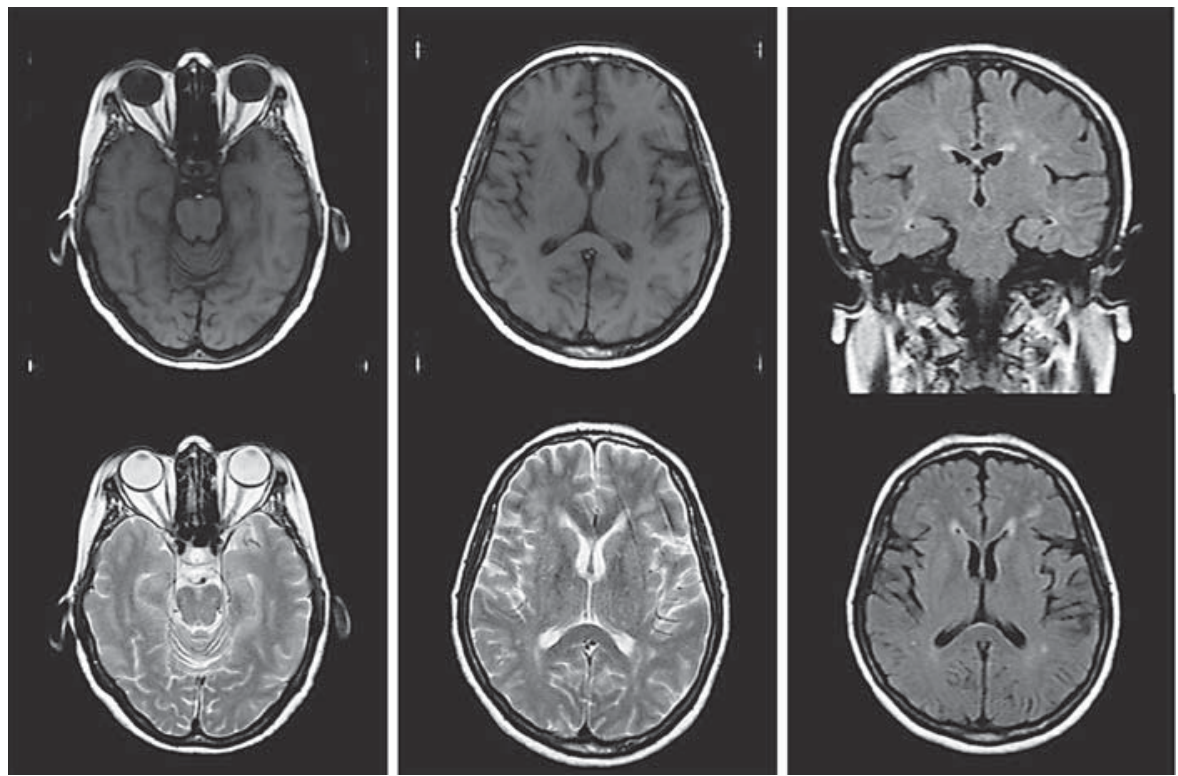

mild slowing of background activity particularly at anterior frontotemporal areas bilaterally. Cranial computed tomography was normal. Brain magnetic resonance imaging (MRI) revealed hyperintensity in basal ganglia, thalami, pons and white matter, with sparing of the cerebral cortices and subcortical white matter. The affected region had isointensity on diffusion-weighted imaging (fig. 1). The antiepileptic drug was given for recurrent generalized seizures. SSZ was stopped. All neurological symptoms and signs resolved 5 days after SSZ was discontinued. On the 30th day after presentation, a new MRI showed resolution of the edema (fig. 2). 


\section{Discussion}

This case showed that central-variant PRES had occurred due to SSZ. In our patient, involvement of the basal ganglia, thalami, pons and temporal pole bilaterally, with sparing of the cerebral cortices and subcortical white matter, was consistent with central variant $[1,3]$. In 2 previously reported cases of reversible encephalopathy caused by SSZ, it was suggested that the potential mechanism of encephalopathy induced by SSZ was delayed hypersensitivity reaction to SSZ or metabolites $[4,5]$.

It may be a difficult differential diagnosis due to nonspecific clinical features and a diversity of radiological findings. Ictal or postictal state, progressive multifocal leukoencephalopathy, severe leukoaraiosis, cerebral autosomal dominant arteriopathy with subcortical infarcts and leukoencephalopathy (CADASIL), infectious encephalitis, acute disseminated encephalomyelitis, mitochondrial myopathy, encephalopathy, lactacidosis, and stroke-like episodes (MELAS) syndrome, vasculitis, and ischemic stroke (watershed or posterior cerebral artery territory) may cause a similar clinical picture $[1,2]$. In our patient, CSF analysis, tests for viral and all vasculitic markers were normal, and regression of the lesion on MRI could support our diagnosis.

The mechanism of PRES is thought to be from abnormalities in the cerebral autoregulatory and endothelial dysfunction. The most reported etiologic factors are hypertension and neurotoxic drugs. In PRES, $70-80 \%$ of the patients had moderate-or-severe hypertension. If the upper limit of autoregulation is exceeded, cerebral blood flow increases and there is a breakdown of the blood-brain barrier. Thus, fluid and blood products exude into the brain parenchyma [6]. In central variant PRES, endothelial cell dysfunction occurring within smaller, perforating vessels supplying the brainstem and basal ganglia is thought to be the pathophysiological process.

Immune system activation leads to endothelial cell activation with release of various mediators in PRES with normal blood pressure. Moreover, endothelial surface antigens and leukocytes increase, then a blood-brain barrier dysfunction occurs leading to vasogenic cerebral edema [7]. In our case there was no history of hypertension and her blood pressure at presentation was at a normal level.

\section{Conclusion}

This was a case of central-variant PRES due to SSZ, and atypical imaging findings should be kept in mind for early diagnosis.

\section{Disclosure Statement}

The authors have no conflicts of interest to disclose.

References

McKinney AM, Jagadeesan BD, Truwit CL: Central-variant posterior reversible encephalopathy syndrome: brainstem or basal ganglia involvement lacking cortical or subcortical cerebral edema. Am J Roentgenol 2013;201: 631-638.

2 Bartynski WS, Boardman JF: Distinct imaging patterns and lesion distribution in posterior reversible encephalopathy syndrome. Am J Neuroradiol 2007;28:1320-1327.

-3 Bartynski WS: Posterior reversible encephalopathy syndrome. Part 1: fundamental imaging and clinical features. Am J Neuroradiol 2008;29:1036-1042.
4 Takahashi H, Ito S, Nagumo K, et al: Salazosulfapyridine-induced encephalopathy with symmetrical lesions in the basal ganglia and thalami. Intern Med 2006;45:927-929.

5 Mut SE, Kutlu G, Ucler S, et al: Reversible encephalopathy due to sulfasalazine. Clin Neuropharmacol 2008;31:368-371.

6 Pedraza R, Marik PE, Varon J: Posterior reversible encephalopathy syndrome: a review. Crit Care Shock 2009;12:135-143.

7 Bartynski WS: Posterior reversible encephalopathy syndrome. Part 2: controversies surrounding pathophysiology of vasogenic edema. Am J Neuroradiol 2008;29:1043-1049.
Ocek/Sener/Demirtas/Ozcelik/Oztekin/ Zorlu 